\title{
Supernova and Nova Explosion's Space Weather: Correlated Megafauna Extinctions, Antarctica Ice Melts and Biosphere Mega-disturbances-Global Warming
}

\author{
William Sokeland \\ Retired Heat Transfer Expert, Spacecraft and Turbine Engines, Oakland City, Indiana 47660, USA
}

\begin{abstract}
Correlation of megafauna extinctions and mega-biosphere disturbances with past supernova explosions has been accomplished by considering a time correction for supernova debris traveling at 88.2325 percent of light speed. Supernova W44 is responsible for the Piora Oscillation which appears to be the biblical event of Noah's Flood. The closest supernova explosion, Vela Jr at 652 light-years, gives the beginning of the greatest historical human disaster, The Black Death. When supernova debris energy input occurs in the northern or southern hemisphere, it causes heating (global warming) in the northern or southern hemisphere, respectively. Long term cooling, the Little Ice Age, occurs in the northern hemisphere when the incoming debris of exploding stars impacts only the southern hemisphere for hundreds of years. Termination of the last ice age results due to melting of numerous supernova impacts that correlate time of impact by changing sea level and geothermal energy released for 2,800 years from the exit crater of Dr. J. Kennet's nano-diamond meteor theory and part of the process involves Dr. O'Keefe's tektite theory. Correlation of Dr. Frezzotti's ice melt Antarctica data with supernova impact times over the past 800 years establishes the Global Warming model in conjunction with the November 2016 Antarctic sea ice melt.
\end{abstract}

Key words: Warming, global, supernova, nova, extinction, ice, crater, meteor.

\section{Introduction}

It is difficult to introduce a topic that has not been addressed in the literature. Scientists generally state that debris from supernova does not impact our planet. They have no concept that incoming particles from exploding stars are focused by our sun's gravity and the magnetic fields of the sun and earth. The focus of the incoming particles is called Cosmic Accumulation of Meteors, CAM and two orbital days called CAM dates are predictable by knowing the impacting debris stream's nova or supernova remnant right ascension, RA. NASA has stated, "The supernova shock wave accelerates electrons, protons, and ions to velocities very close to the speed of light." Since ions are mentioned, we may have all positively charged atoms that exist in number in the solar wind with a limit of

Corresponding author: William Sokeland, MSc, scientist, research fields: turbine engines, spacecraft, comets, tornadoes, hurricanes, and earth thermal conditions. the atomic mass of iron.

Some simple mathematics are applied to this subject.

$\mathrm{V} / \mathrm{C}=\Delta \mathrm{T}_{\mathrm{L}} /\left(\Delta \mathrm{T}_{\mathrm{L}}+\left[\mathrm{ETA}-\mathrm{T}_{\mathrm{L}}\right]\right)=$ fraction of light velocity (Vela JR - Plague 0.875367) (SN 1006 $0.882325)$ (SN $1054-0.879060)$

ETA $=0.13337 \Delta \mathrm{T}_{\mathrm{L}}+\mathrm{T}_{\mathrm{L}}=$ year of impact $\Delta \mathrm{T}_{\mathrm{L}}=$ light years to remnant $\mathrm{T}_{\mathrm{L}}=$ age of remnant

$\mathrm{RA}=24(\mathrm{DOY}-79) / 365=$ right ascension $(\mathrm{DOY}=$ day of year, eastern terminus)

$\mathrm{L}=13 \mathrm{~W}+360(15-\mathrm{RA}) / 24=$ western terminus longitude

Moves Base Point, 13W: negative $(\mathrm{RA} \geq 15)=$ east and positive $(\mathrm{RA} \leq 15)=$ west

The following equations are used to find the western terminus longitude for an old remnant.

$\mathrm{S}=360$ ETA $(5.5) /(100 \times 60 \times 24)$ the shift of the western terminus always moves to west

$\mathrm{IL}=\mathrm{L}-\mathrm{S}=$ Impact western terminus longitude at 
ETA (years ago).

You must use common logic when using the equations. For example if the DOY was 5 , you would have to add 365 because there are no negative right ascensions. If you are calculating right ascension from the third equation, you must use the DOY for the eastern terminus. When you know the DOY for one terminus, the DOY for other terminus is half a year away at the other side of the orbit of the earth and both dates are CAM dates. When you know the longitude of one terminus, the longitude of the other terminus on the earth is 180 degrees away on the other side of the planet.

\section{Method}

As for method, I have simply scanned the internet for data and preformed the calculations to see if the data match the Supernova and Nova Impact Theory, SNIT. I am grateful for the use of many figures created by other authors. If I have used one of your figures, I extend my thanks to you. The question that I am trying to answer is, "Is global warming caused by man made carbon dioxide emissions or is the increase of carbon dioxide being experienced simply as a byproduct of the proposed phenomenon of a supernova or nova debris streams impacting the planet?" If you read my work, you will note that many harmful effects are possible in the Supernova and Nova Impact Theory, SNIT, including extreme changes of the climate.

\section{Discussion}

\subsection{Supernova Debris Extinctions}

Noted megafauna extinctions in the past 50,000 years are correlated with the times when the debris of supernova explosions impact earth. The time of extinction should be near the time of impact of a supernova debris stream. The time of impact is derived from the time the light of the supernova explosion was seen on earth by adding a correction for the fact that the debris from the explosion moves slower than the speed of light and is shown in the second equation. The severity of the extinction will depend on the distance of the supernova from our planet, the type supernova that indicates the power of the explosion and the surroundings of the supernova when it explodes. In general, most major disturbances of earth's biosphere can be attributed to the explosion of supernovas. Some of the extreme examples are presented.

It is known that the neutrino is the particle that escapes from a supernova explosion and travels very near the speed of light to surrounding bodies. The measured increase in the number of neutrinos by underground sensors is the method we use to detect the time of the arrival of light from a nova or supernova explosion at our planet [1]. Just as the neutrinos impact our planet, particles of larger mass than the neutrino moving at a slower velocity will also impact our planet. By using the distance to SN 1006 from earth, 7,543 light years; lys; the time the light of the explosion was seen, $1006 \mathrm{AD}$; and the arrival time of the debris that causes the warmest year on record, $2012 \mathrm{AD}$, the constant of 0.13337 may be formally derived using the first equation $[2,3]$. The derivation proves that the debris streams that cause megafauna extinctions or large animal die offs are travelling at 88.2325 percent of light speed.

The model proposed assumes the remnant or pulsar of the exploded supernova is surrounded by moving hollow spheres of particles that have a wall thickness. The sphere farthest from the remnant or pulsar is composed of neutrinos, the particles escaping from the explosion with the least mass. Each hollow sphere composed of particles of different mass travels with a constant velocity and the sphere that normally causes the extinction is composed of small particles of positive electrical charge. Due to the electrical charge of the particles, the particles will separate and cause the thickness of the wall of the hollow sphere to increase as the hollow sphere travels from the location of the explosion to the planet where the extinction 

Melts and Biosphere Mega-disturbances-Global Warming

occurs. The wall thickness of the hollow sphere will increase as the sphere travels away from the explosion because of the electrical force of repulsion acting on particles of the same positive charge. The thickness of the wall flowing past the planet may cause the death of animals to occur for years before the wall of destructive particles passes the planet particularly when the explosion was very distant from our planet.

The focusing effect of the sun's gravity and the magnetic fields of the sun and earth cause the destructive increase of the debris stream density and the CAM at particular times and locations on our planet.

The supernova remnants are listed in order in Table 1 with the distance from our planet to the remnant dictating the order and indicating the probable severity of the extinction or animal deaths. The most powerful supernova is type 1a. As a result, more animal deaths are expected for a type 1a as compared to a type II at the same distance. The correction for the difference between the time of impact and the time the light of the supernova explosion was seen results because the particles in the extinction, hollow sphere travel at a speed less than the speed of light. When the light of the supernova explosion was seen within the last century, the correction term is very important. When the explosion was hundreds of thousands of years ago, the correction term can be ignored. The correction term is equal to the distance in light-years, lys, to the supernova remnant times the constant 0.13337 and has the unit of years, yrs. The error in the analysis of megafauna extinctions will be in the inaccuracy of the unobserved time the light was seen, the distance to the supernova, the effect of wall thickness, and the tolerance on the time of the megafauna extinctions.

Since the unfocused particle, hollow sphere has a wall thickness with very low and variable particle density; the hollow sphere is not detectable when traveling through space by modern means. After the focused particle, initial blast on the planet passes, the hollow sphere particle mass decreases and then increases as the center of the hollow sphere of particles is approached.

Table 1 Times of supernova debris impact (past and future) [4].

\begin{tabular}{lllll}
\hline Supernova/Type & Distance (lys), $\Delta \mathrm{T}_{\mathrm{L}}$ & Light seen or age, $\mathrm{T}_{\mathrm{L}}$ & Correction (yrs) & Impact time, ETA \\
\hline Vela Jr/? & 652 & $1250 \mathrm{AD}$ & 87 & $1337 \mathrm{AD}$ \\
Vela/II & 800 & 11,000 to 12,500 ya & 107 & 10,893 to 12,393 ya \\
Veil Nebula \& Cygnus Loop/? & 1,470 & 5,000 to 8,000 ya & 196 & 4,804 to 7,804 ya \\
GK Persei/1a & 1,500 & $1901 \mathrm{AD}$ & 200 & $2101 \mathrm{AD}$ \\
Simesis 147/? & $3,000 \pm 350$ & 40,000 ya & 400 & 39,600 ya \\
SN 393 (RX J1713.7-3946)/? & 3,620 & 1,607 ya & 483 & 1,124 ya \\
Puppis A/? & 7,000 & 3,700 ya & 934 & 2,766 ya \\
SN 1054 (Crab)/II & 7,175 & $1054 \mathrm{AD}$ & 1,021 & $2010 \mathrm{AD}$ \\
SN 1006/1a & 7,543 & $1006 \mathrm{AD}$ & 1,006 & $2012 \mathrm{AD}$ \\
SN 185/1a & 8,154 & $185 \mathrm{AD}$ & 1,087 & $5 \mathrm{AD}$ \\
RCW 103/? & 10,000 & $1 \mathrm{st}$ century & 1,334 & 566 ya \\
W44/? & 10,000 & 6,500 ya & 1,334 & 266 ya \\
SN 386, G11.2-0.3/II [10] & 16,000 & $1,900 \pm 500$ ya & 2,134 & 17,600 ya \\
SN W50/? & 18,000 & 20,000 ya & 2,400 & 31,532 ya \\
Sagittarius A East/? & 26,000 & 35,000 ya & 3,468 & 46,304 ya \\
Kesteven 79, G33.6+0.1/? & 27,710 & 50,000 ya & 3,696 & 2,439 ya \\
G296.7-0.9/? & 31,948 & 6,700 ya & 4,261 & 1,551 ya \\
G43.3-0.2/? & 32,610 & 5,900 ya & 4,349 & \\
\hline
\end{tabular}


Table 2 Impact times compared to extinction times for recorded mass extinctions [8].

\begin{tabular}{|c|c|c|c|}
\hline Supernova & Impact time, ya & Extinction location & $\begin{array}{l}\text { Extinction time, ya/west terminus, } \\
\text { long degrees/modified terminus range } \\
\text { in red }\end{array}$ \\
\hline SN $185 \mathrm{X}$ & 1272 AD (728 ya) & New Zealand-2nd extinction 165E 45S & 750/WT 18W 25W 155E \\
\hline Vela Jr & $1337 \mathrm{AD}(663$ ya) ** & $\begin{array}{l}\text { Black Death India } \\
70 \mathrm{E} 25 \mathrm{~N}\end{array}$ & $1334 \mathrm{AD}(666) / \mathrm{WT} 105 \mathrm{~W} 114 \mathrm{~W} 66 \mathrm{E}$ \\
\hline W50 Meteor (70\% C) & 12,800 & North America & $13,000[8]$ \\
\hline W50 Meteor $(70 \% \mathrm{C})$ & 12,800 & South America $60 \mathrm{~W}$ & 12,500 [8]/WT 110.5W 79E $101 \mathrm{~W}$ \\
\hline Steam & 11,700 уа & Cyprus & $10,000[8]$ \\
\hline $\begin{array}{l}\text { Veil Nebula and } \\
\text { Cygnus Loop X }\end{array}$ & $\begin{array}{l}4,804 \text { to } 7,804 \\
(6,304 \text { average })\end{array}$ & Antilles & 6,000 \\
\hline Simeis $147 \mathrm{X}$ & 39,600 & Tasmania $150 \mathrm{E}$ & 41,000/WT 153W 23E 157W \\
\hline SN 393 & $1,143 * *$ & Madagascar 45E 17S & 1,000/WT 20E 5E $175 \mathrm{~W}$ \\
\hline G43.3-0.2 X & $1,551 * *$ & New Zealand $-1^{\text {st }}$ extinction $165 \mathrm{E} 45 \mathrm{~S}$ & 1,200/WT 50E 32E 148W \\
\hline Puppis A X & 2,833 to 2,766 & New Caledonia 21S 166E & 3,000/WT 110.5W 148W 32E?? \\
\hline SN RCW 103 & $566 * *$ & Madagascar Lemur & 500/WT 6.5E 0W 180E \\
\hline $\begin{array}{l}\text { Maunder Minimum } 1605 \\
\text { X }\end{array}$ & 418 & Mascarenes 20S 57E & 400/WT \\
\hline SN W44 Dec. 1 18m 58s & 5,166 & Piora Oscillation [14] & 5,100/WT 46E 25W 155E \\
\hline G296.7-0.9 X & $2,439[11] * *$ & Madagascar 45E 16S & 2,000/WT 59.5W 89W 91E \\
\hline G11.2-0.3 X & $266 * *$ & Commander Islands 55N 167E & 250/WT 35E $145 \mathrm{~W}$ \\
\hline SN W50 & 17,600 & Ice Age Maximum \& Declining & 18,000 [9]/WT 50E 170E $10 \mathrm{~W}$ \\
\hline HB 21(G89.0+4.7) & 18,628 & Populations & WT 73E 177E $3 \mathrm{~W}$ \\
\hline Sagittarius A East X & 31,532 & Japan $135 \mathrm{E} 35 \mathrm{~N}$ & $30,000 / \mathrm{WT} 28.25 \mathrm{E} 46 \mathrm{~W} 134 \mathrm{E}$ \\
\hline $\begin{array}{l}\text { Kesteven } 79(\mathrm{G} 33.6+0.1) \\
\mathrm{X}\end{array}$ & 46,304 & Australia $120-150$ E $20 \mathrm{~S}$ & 46,000/WT 45.5W 129E $51 \mathrm{~W}$ \\
\hline
\end{tabular}

Due to the scattering of light for small particles, the sunspots will tend to disappear when a hollow sphere of small particles enters our solar system between the sun and the earth. Other signs of the presence of the small particles are the increase of animal die offs for birds, bees, and fish and a decrease in TSI (total solar irradiance) [5]. Recent outstanding examples of animal and human die offs due to the incoming debris were the Saiga antelope in Asia in May of 2014 and people dying in India in May of 2015-2016 [6, 7]. These die offs were caused by SN 1006 and would have been called megafauna extinctions if the populations were restricted to small island land areas. The deaths of the destructive hollow spheres for supernovas 1054 and 1006 will be minimal in the beginning but will increase in intensity as the years of higher particle mass and densities are approached. Since these supernovas are over 7,000 light-years away from our planet, the effects should not be as severe as the extinctions listed in Table 2 that were due to supernova remnants that were closer to our planet.

The western terminus, WT, noted in Tables 2 and 3 is the longitude location in degrees for the Center of the effective debris zone of the supernova noted. The red numbers are the range for the western and eastern termini modified for right ascension drift in time by the fifth and sixth equations. Extinction locations should appear in or near this red number 180 degree zone and preferably at a terminus because this is where the particles are concentrated. The blue numbers in Table 2 indicate an extinction match for the supernova terminus.

The impact times denoted by ** in Table 2 are times when plague outbreaks are noted in conjunction with megafauna extinctions. If the megafauna extinction is in recorded history, it is always accompanied by the plague. Both of these phenomena 

Melts and Biosphere Mega-disturbances-Global Warming

are caused by the supernova debris stream.

The blue diamonds in Figs. 1 and 2 are the megafauna extinction times and the red squares are the predicted impact times for the supernova debris. Twelve megafauna extinction times are shown in the cited reference and ten of these extinctions are correlated with the impact times of supernova debris. The missing North and South American extinctions are due to the supernova W 50 meteor strike. The
Maunder Sunspot Minimum case is plotted, but the supernova is unknown. The megafauna extinction data reported have never before been correlated by a particular phenomenon [8]. Figs. 1 and 2 show the excellence of the correlation for the ten cases.

Supernova 393 does not show as a megafauna extinction in the reference list, but an extinction of giant lemur occurs at $1000 \mathrm{AD}$ at Madagascar that is not included in Figs. 1 and 2.

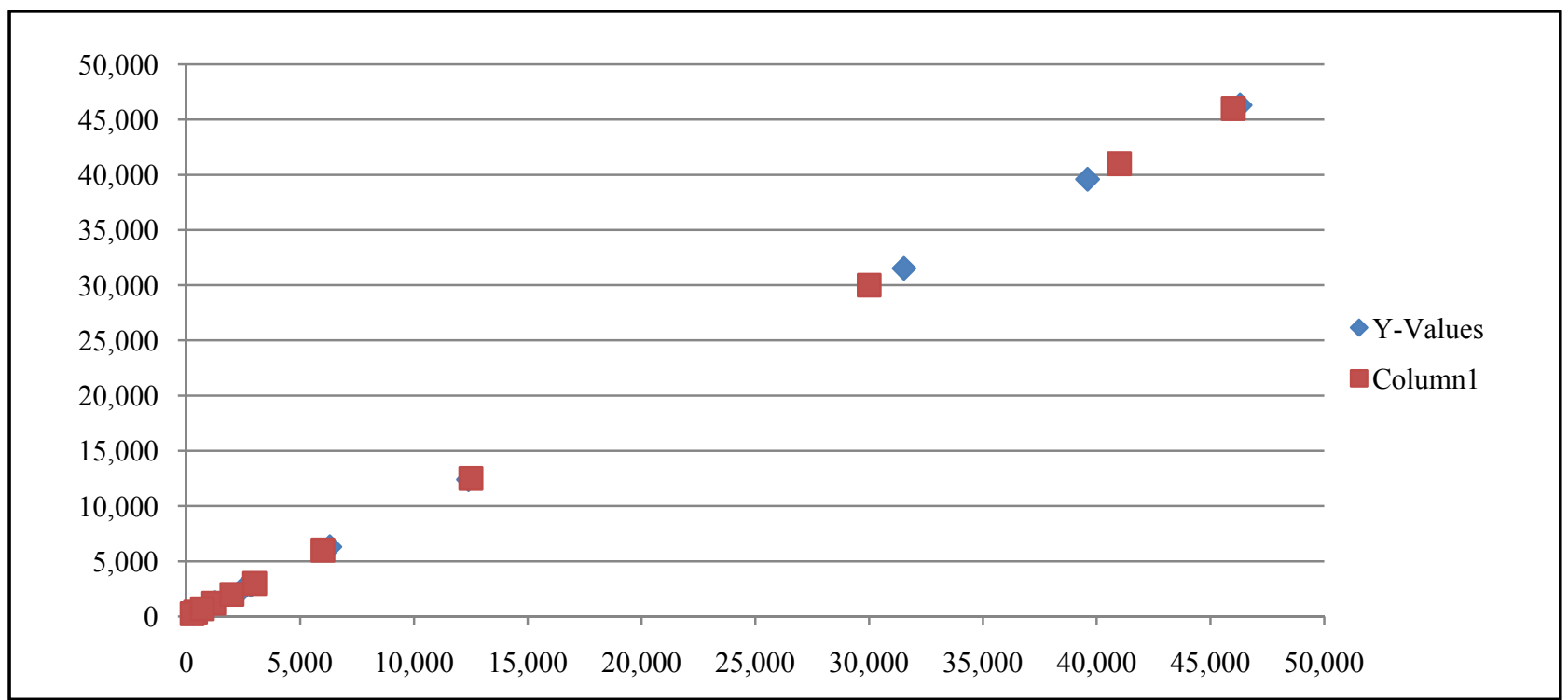

Fig. 1 Correlation between impact times and extinction times (0 to 50,000 ya).

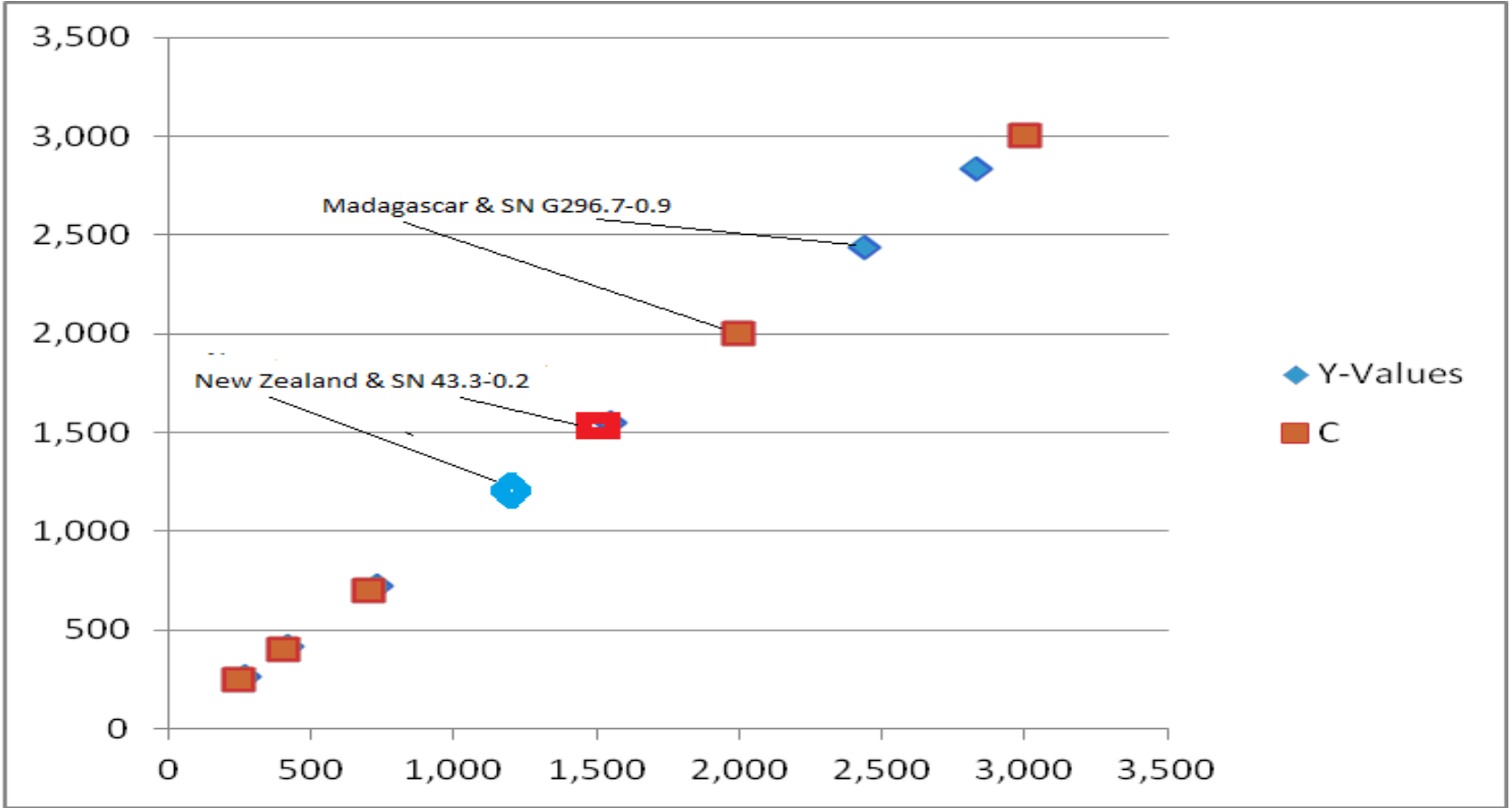

Fig. 2 Correlation between impact times and extinction times (0 to 3,500 ya). 


\subsection{Pictorial Explanation of Termini}

The definition of the eastern terminus is shown in Fig. 1a. The definition for the western terminus is the same with the position of the sun and the earth reversed in Fig. 1a.

Fig. 1b shows the eastern and western termini separated by 180 longitude degrees and the small circles represent northern and southern focal points indicating maximum particle densities due to the magnetic field of earth causing a magnetic bottle at the two different termini or CAM dates. A CAM date is the specific day of the year that maximum cosmic accumulation of meteors, CAM occurs.

\subsection{Special Cases}

SN Kesteven 79 or G33.6+0.1 is an interesting example for researcher age and distance. One reference, proposing a new theory, gives a distance of 7.1 Kilo-parsecs, kpc, and an age of 6,000 years [38], while an older reference, by the established old method, gives a distance of $8.5 \mathrm{kpc}$ and an age of 50,000 years [39]. The theory that megafauna extinction occurs due to supernova debris impact with our planet agrees with the distance and age of the old method. Since distances and ages of supernova remnants are always under debate, the selection of distances and ages for this work at times is at the

\section{Eastern Terminus}

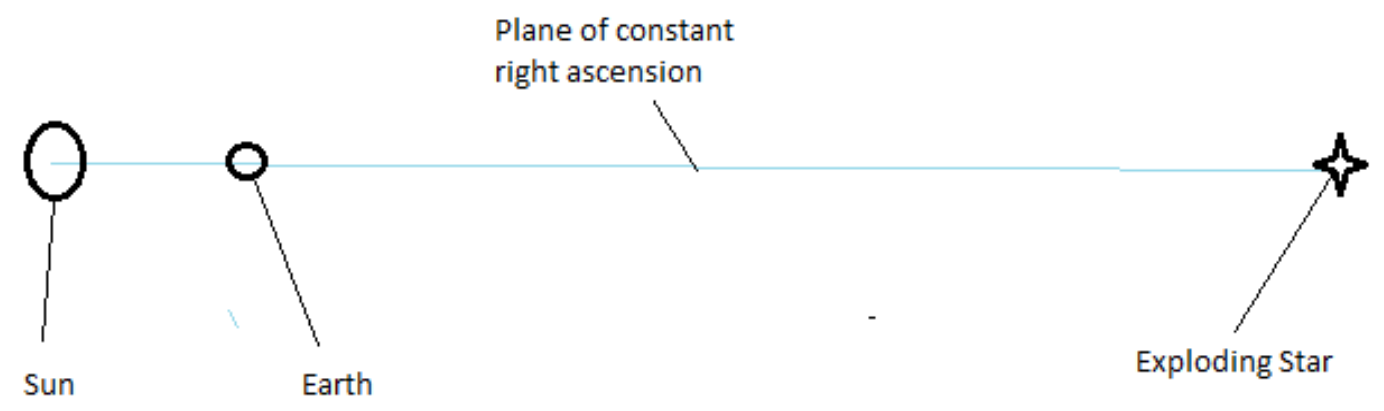

Fig. 1a Pictorial definition of eastern terminus.

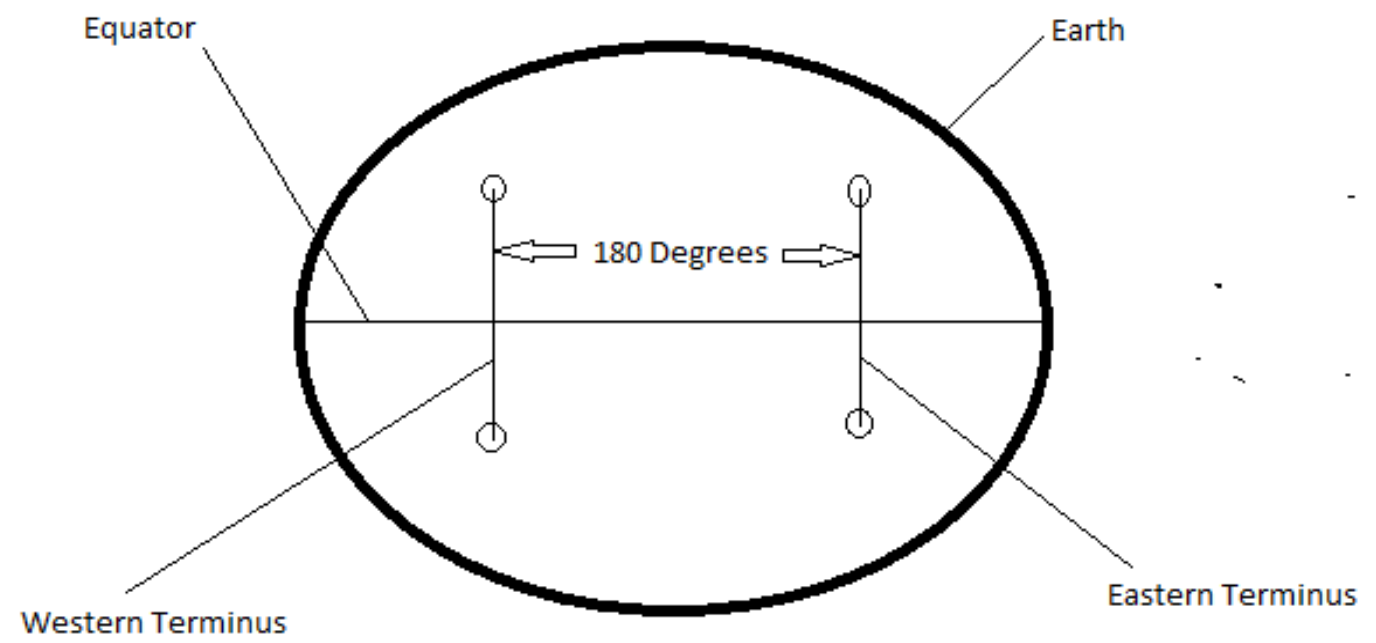

Fig. 1b Western and eastern termini with magnetic bottle northern and southern focal points. 
author's digression.

A future supernova explosion of extraordinary possibilities for earth is shown in Table 1 as GK Persei. The distance of this supernova explosion is near the value of the distance for the explosion that correlates with the Antilles extinction, but the supernova type is $1 \mathrm{a}$, the most powerful supernova, indicating a severe, coming extinction to be near or after the year 2101. The impact of GK Persei will be 25 times more powerful than SN 1006. By watching the results of SN 1006 in Eurasia, the future effects of GK Persei can be estimated. The longitude range on earth of the extinction due in $2101 \mathrm{AD}$ from GK Persei is $175 \mathrm{E}$ to $5 \mathrm{~W}$. The preliminary indication is that North America, South America and Western Europe will experience the brunt of the Great Tribulation while Eastern Europe, Australia, and Asia will be barely touched.

\subsection{Sunspots}

The nine latest supernova debris extinctions or impact times noted in Table 2 are at 266, 418, 566, $663,728,1,143,1,551,2,439$, and 2,833 ya. As previously stated, decreases in the number of sunspots should be expected when small particles of supernova debris are in our solar system between the sun and our planet. Recorded dates of sunspot minimums are: Gleissberg minimum 1880-1914 AD (120-86 ya), Dalton minimum 1790-1830 AD (210-170 ya), Maunder minimum 1605-45- 1715 AD (395-355-285 ya), Sporer minimum 1430-50 - 1550 AD (570-550 450 ya), Wolf minimum 1280-1350 AD (720-650 ya), and Oort minimum 1040-1080 AD (960-920 ya). Other sunspot minimums are (360) BC (2360 ya), Homeric minimum 950-800 BC (2,950-2,800 ya), and (765) BC (2,765 ya) [16, 17]. Many sunspot minimums have a corresponding supernova and extinction in this study. Recent exceptions are the Gleissberg and Maunder minimums. A plot of 14 carbon residual minimums shows a correspondence with sunspot minimums and a carbon 14 minimum is shown at 439 BC corresponding with SN G296.7-0.9 at the same time in Fig. 3 and the 2,437 ya extinction [35]. The correlation between extinction and sunspot minimums is color coded in this paragraph. It should be noted that the beginning of the supernova has a strong correlation with the beginning of the sunspot minimum, but extinctions and plagues may occur at any time during the debris stream time period.

\subsection{TSI Data and Antarctica Ice Melts}

The scattering of solar energy due to the small particles of supernova debris is also reflected in TSI data as shown in Fig. 3. The timing of impact for supernova debris streams allows the identification of the times and duration time periods for supernova debris streams impacting our planet. Fig. 3 indicates the duration of a single supernova debris stream flowing past our planet is at least 50 years and at times more than 100 years. The duration of the time period is due to the thickness of the hollow sphere of incoming particles.

Fig. 6 of Ref. 18 indicates there are other supernova impacts that have not been addressed by this study.

In Fig. 3, a supernova TSI cycle is shown by a down stroke and an upstroke in the classic form generated by SN G296.7-0.9 that is ended by supernova G299. Smaller irradiance changes are produced by nova impacts but the TSI reduction time range is smaller. Fig. 3 shows an excellent correspondence between sunspot minimums, irradiance depressions, and supernova impact times. The six smaller dips in TSI generated by nova WZ Sagittae in the red portion of the TSI curve of Fig. 3 beginning with the Dalton minimum indicate we have been impacted by six different debris streams from the nova. The last one was in the 1965 to 1970 time region and it is the debris stream of Nova WZ Sagittae that started our current global warming episode near 1966.

All of the supernovas shown in Fig. 3 starting with SN 393 1,143 years ago to our current time have 


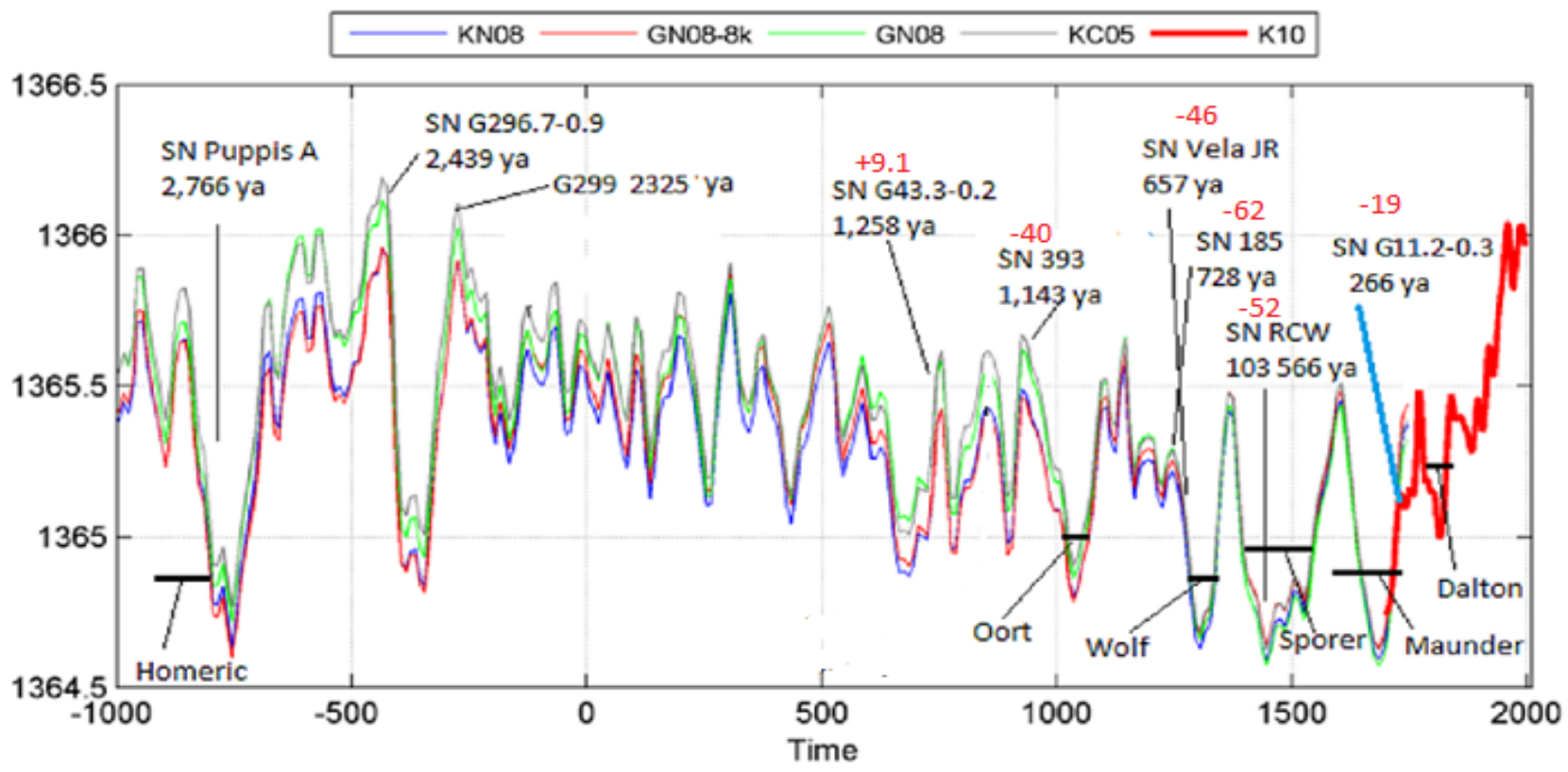

Fig. 3 Irradiance, supernovas and sunspot minimums [18].

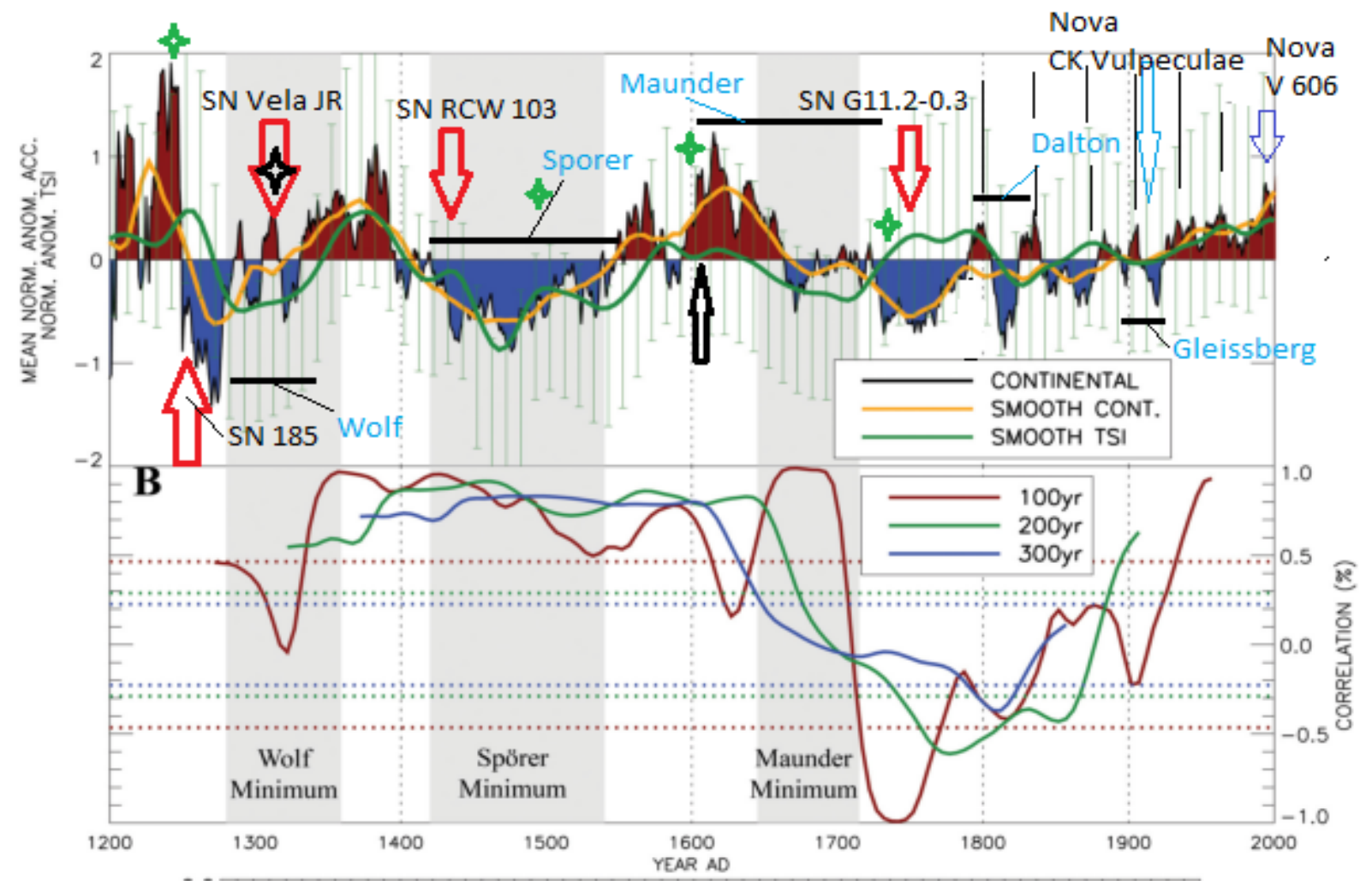

Fig. 3a Antarctic ice melts, extinctions, supernova.

negative declinations noted by the red numbers. This means they are depositing the major part of their debris stream energy on our planet in the southern hemisphere. This time period represents the Little Ice
Age that only occurred in the northern hemisphere. Supernovas that caused Antarctic ice melts for the last 800 years are shown in Fig. 3a. If nova WZ Sagittae that has a declination of +17 degrees did not supply 
energy to the northern hemisphere during this time period, conditions would have been colder during the Little Ice Age.

Fig. 3a indicates the Commander Islands extinction is correlated with SN G11.2-0.3 and occurs near the end of the Maunder sunspot minimum and at the beginning of a large ice melt with no associated sunspot minimum indicating no decrease in TSI, causing the loss of the cited correlation between TSI and MNAA (mean normal anomaly accumulation). Fig. 3 shows the first change in the slope of the red data line indicating a supernova strike and is noted by the blue line connection to SN G11.2-0.3. The Maunder minimum in conjunction with the corresponding TSI depressions shown in Fig. 3 indicates a missing supernova that is also noted in Fig. 3a. The location of the missing supernova is shown as a black arrow in Fig. 3a. The black vertical lines shown in Fig. 3a starting at the Dalton sunspot minimum are Leonids meteor showers that are associated with super outbursts of the recurrent nova WZ Sagittae. The six Leonids outbreaks correspond to the six discontinuities shown in the red data of Fig. 3. The time spacings of the Leonids meteor showers are near 33 years which corresponds to the spacings of three recent super outbursts of nova WZ Sagittae, 1913, 1946, and 1978. Applying the constant, 0.13337, times the 142 lys distance to WZ Sagittae gives 19 years travel time for the nova debris stream to impact earth. The addition of the travel time to the noted years of super outburst produces impact times of 1933 and 1966 that closely match the last two vertical black lines shown in Fig. 3a and the last two discontinuities of the red data line in Fig. 3.

The single nova impact strikes of CK Vulpeculae 1910-12 and Nova V 606 Aquilae 1989 are shown by downward blue arrows in Fig. 3a. Nova CK Vulpeculae impact time agrees with the Gleissberg sunspot minimum.

The correlation of timing for impacting debris streams in Fig. 3a is very important because the range of the $\mathrm{x}$ axis is only 800 years giving more accuracy than Figs. 3 or 4 whose ranges of the $x$ axis are 3,000 years and 11,000 years, respectively. This means the placement of the red arrows is more accurate with respect to the blue melting regions in Fig. 3a.

There is a small mystery as to why SN G11.2-0.3 does not have an associated sunspot minimum and the solution deals with the understanding of the geometry of shading between sun and earth for remnants of near equatorial declinations.

It should also be noted that Fig. 3a implies a minimum heating effect for SN Vela Jr. This occurs because the heating effect of the Vela Jr supernova is being opposed by the cooling effect of SN 185 .

\subsection{SN 1006 Antarctic Ice Melting}

Since the incoming energy of supernova acts in particular hemispheres with respect to the earth's temperatures, SN 1006 with a declination of -46 degrees which is currently acting should cause increased temperatures in the southern hemisphere and as far up as southern Asia (India) and the Barents Sea in the northern hemisphere. The increase in temperature in the southern hemisphere should start to melt ice in the Antarctic after 2012, the beginning year for SN 1006 impact [36]. The beginning of the Antarctica ice melt was noted in October 2014 and became big news in November 2016. November $2^{\text {nd }}$ is the CAM date for the eastern terminus of supernova 1006.

\subsection{Past Unusual Biosphere Disturbances}

Supernova 393 debris impacted earth near 857 AD and started the Medieval Warming Period. When the warm part of the supernova oscillation or cycle stopped and the cooling occurred, the Little Ice Age began near 1250 AD. Supernova 393 also caused the decline of the Mayan Empire near 900 AD. Supernova 393 is proposed to have caused a gamma ray attack upon earth 1,200 years ago [44].

The effect of supernova debris becomes very 
interesting when considering the fall of ancient empires. One possible example is the end date of the third intermediate period of Egypt at $712 \mathrm{BC}$ [12]. This was one of Egypt's most prosperous periods. The date corresponds with the impact date of the Puppis A supernova at $766 \mathrm{BC}$.

Supernova G29.6+0.1 impacted earth 3,652 years ago. The date of the biblical plagues that freed Jacob's seed appears to be $1446 \mathrm{BC}$ [34].

Supernova G32.0-4.9 impact time of 4,530 ya corresponds to the fall of Egypt's fourth dynasty in 2494 BC [20]. It is reported that Ancient Europeans vanished 4,500 years ago [31]. Could supernova debris actually destroy the structure of an empire and change DNA in Europe? An impact time of 4,210 years ago matches the 4.2 Kiloyear Event [25].

Finally the question of a supernova like SN W44 that is not in our megafauna analysis is addressed. Its age is 6,500 yrs and it is 10,000 light-years from earth giving an impact time of 5,166 ya [13]. Megafauna extinctions occurred 5,000 ya; the woolly mammoth, the giant ground sloth, and the giant deer. The Piora
Oscillation, Noah's flood, or Holocene dark ages are names associated with this impact [15]. The climate of Egypt changed from a wet savannah to a desert. It is said that the arctic pole ice melted and refroze and extreme rains caused extensive flooding. If the debris impact drove an extreme amount of moisture from the arctic ice cap and the oceans of the northern hemisphere, clouds could have caused the greenhouse effect to melt a significant portion of the arctic ice cap because water is a greenhouse gas. When the clouds were dissipated, years after they were formed, the arctic ice cap refroze but did not reach its previous southern latitude and as a result the northern hemisphere rain bands shifted to the north and Egypt and northern Africa became a desert. It should be concluded that SN W44 is not a classic supernova and the extinction associated with this event is due to a great flood and land animal remains were washed into the oceans and destroyed by marine scavengers causing entombed bodies in the strata to be rare for this period of time.

Supernova G82.2+5.3 in Table 3 with an impact

Table 3 Declinations, supernova debris impact times for unusual changes of empires and biosphere disturbances [19].

\begin{tabular}{|c|c|c|c|c|c|}
\hline Supernova & Distance (lys) & Light seen (ya) & Correction (yrs) & Impact time (ya) & Declination/west terminus \\
\hline G11.2-0.3 & & & & 266 & -19 \\
\hline RCW 103 & & & & 566 & -52 \\
\hline SN 185 & & & & 728 & -62.5 \\
\hline Vela Jr & & & & 657 & -46 \\
\hline SN 393 & & & & 1,143 & $-40 / \mathrm{WT} 20 \mathrm{E}$ \\
\hline G43.3-0.2 & & & & 1,551 & $+9.1 / \mathrm{WT} 50 \mathrm{E}$ \\
\hline G296.7-0.9 & & & & 2,439 & -63 \\
\hline G299 & 16,310 & 4,500 & 2,175 & 2,325 & -45 \\
\hline Puppis A & 7,000 & 3,700 & 934 & 2,766 NC 165E Egypt & $\begin{array}{l}-42 / \mathrm{WT} 110.5 \mathrm{~W} ? \\
\text { /WT } 110.5 \mathrm{~W}\end{array}$ \\
\hline $\mathrm{G} 29.6+0.1$ & 32,600 & 8,000 & 4,348 & 3,652 & $-3 / \mathrm{WT} 42.5 \mathrm{E}$ \\
\hline G32.0-4.9 & 6,520 & 5,400 & 870 & 4,530 & $-3 / \mathrm{WT} 48.5 \mathrm{E}$ \\
\hline SN W44 & 10,000 & 6,500 & 1,334 & 5,166 & $+1 / \mathrm{WT} 45.5 \mathrm{E}$ \\
\hline G82.2+5.3 (W63) & 5,216 & 6,600 & 696 & 5,904 & $+45 / \mathrm{WT} 66.5$ \\
\hline G57.2+0.8 & 18,758 & 10,000 & 2,502 & 7,498 & $+21 /$ WT $51.5 \mathrm{E}$ \\
\hline $\mathrm{G} 31.9+0.0$ & 29,304 & 12,000 & 3,908 & 8,092 spi $170 \mathrm{~W}$ & $-0 / \mathrm{WT} 44 \mathrm{E}$ \\
\hline SN W51C & 14,018 & 10,000 & 1,870 & 8,130 & $+14 / \mathrm{WT} 15 \mathrm{E}$ \\
\hline Vela & & & & 11,700 & -45 \\
\hline G109.1-1.0 & 15,322 & 17,000 & 2,043 & 14,957 & +59 WT 107E? \\
\hline SN W50 & 18,000 & 20,000 & 2,401 & 17,600 & $+5 \mathrm{WT} 50 \mathrm{E}$ \\
\hline HB 21 & & & & 18,628 & +50 \\
\hline Kes 79, G33.6+0.1 & 27,710 & 50,000 & 3,696 & 46,304 & $-0 / \mathrm{WT} 45 \mathrm{E}$ \\
\hline G192.8-1.1 & 13,040 & 78,000 & 1,739 & 76,251 & +17 \\
\hline
\end{tabular}


time of 5,903 ya produced the 5.9 Kiloyear Event and it is so close in time to the Piora Oscillation that the two different events due to different supernovas are often considered the same event [21].

Supernova G57.2+0.8 impact time of 7,498 ya corresponds with 7,400 year old burial ponds in Florida and extremely stormy weather noted by the destruction of pine trees [45].

Supernova G31.9+0.0 impact time of 8,092 ya produces another correlated woolly mammoth extinction event at Lake Hill on St Paul Island in the Bering Sea 7,600 years ago. The climate change produced by this supernova caused these mammoth to die due to lack of fresh water or drought [22].

Supernova W51C provides the impact time of 8,130 years ago and this date coincides with the end of the 8.2 Kiloyear Event [26].

The W50 meteor at 12,800 ya matches the beginning of deglaciation in Antarctica 12,500 years ago [27]. Supernova Vela has a range of impact times shown in Table 1 and Fig. 7 suggests the change of temperature date of 11,700 years ago should be used. Vela's thermal impact in the northern hemisphere was large because it is the second closest supernova to our planet.

Supernova G109.1-1.0 at an impact time of 14,957 ya appears to have changed the DNA of humans 15,000 years ago at the end of the last ice age [23]. DNA changes near supernova impact times suggest changes in the genes of organisms. This may have an impact on the concept of evolution and prove why the missing link will always remain missing.

Supernova W50 with an impact time of 17,600 ya and a declination +4 appears to have caused rapid melting of the Patagonian ice sheet 17,500 years ago and corresponds to the last glacial maximum of 18,000 years ago $[24,27]$.

Supernova G192.8-1.1 with an impact time of 76,251 ya appears to be in the same category as supernova W44 because it corresponds with the Toba eruption dated 75,000 \pm 900 years ago. The eruption data range includes the predicted impact of supernova G192.8-1.1 and this coincides with a famous bottleneck of the world's human population.

The maximum time difference for the events in Table 4 and the time of supernova impact are reasonable.

Table 4 Supernova impact versus biosphere disturbance times.

\begin{tabular}{|c|c|c|c|c|}
\hline Supernova & Impact time (ya) & Biosphere disturbance & Disturbance time (ya) & $\begin{array}{l}\text { Maximum time } \\
\text { difference (years) }\end{array}$ \\
\hline Sn 393 & 1,143 & $\begin{array}{l}\text { Medieval Warming Period, Fall of } \\
\text { Mayan Empire \& Gamma Rays }\end{array}$ & 1,143 & 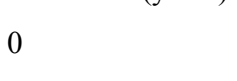 \\
\hline Puppis A & 2,703 & $\begin{array}{l}\text { Fall of third intermediate period of } \\
\text { Egypt }\end{array}$ & 2,712 & 9 \\
\hline G32.0-4.9 & 4,472 & $\begin{array}{l}\text { Fall of Egypt's fourth dynasty \& } \\
\text { vanished Europeans } \\
4.2 \text { Kiloyear Event }\end{array}$ & $\begin{array}{l}4,494 \& 4,500 \\
4,200\end{array}$ & $\begin{array}{l}22 \& 28 \\
272\end{array}$ \\
\hline SN W44 & 5,076 & Piora Oscillation & 5,100 & 24 \\
\hline G82.2+5.3 (W63) & 5,857 & 5.9 Kiloyear Aridification Event & 5,900 & 43 \\
\hline G57.2+0.8 & 7,498 & $\begin{array}{l}\text { Florida Burial Ponds } \\
\text { Storm Dead Trees [37] }\end{array}$ & 7,400 & 98 \\
\hline $\mathrm{G} 31.9+0.0$ & 8,092 & $\begin{array}{l}\text { St Paul Island, Woolly Mammoth } \\
\text { Extinction }\end{array}$ & 7,600 & 492 \\
\hline SN W51C & 8,130 & 8.2 Kiloyear Event & 8,200 & 70 \\
\hline G109.1-1.0 & 14,957 & Human DNA change & 15,000 & 43 \\
\hline SN W50 & 17,437 & $\begin{array}{l}\text { Rapid melting Patagonian ice sheet } \\
\text { and Last Glacial Maximum }\end{array}$ & 17,600 & 163 \\
\hline HB 21 & 18,628 & Last Glacial Maximum & 18,000 to 17,000 & 600 to 1,628 \\
\hline G192.8-1.1 & 76,143 & Human population bottleneck & $75,000 \pm 900$ & 693 \\
\hline
\end{tabular}




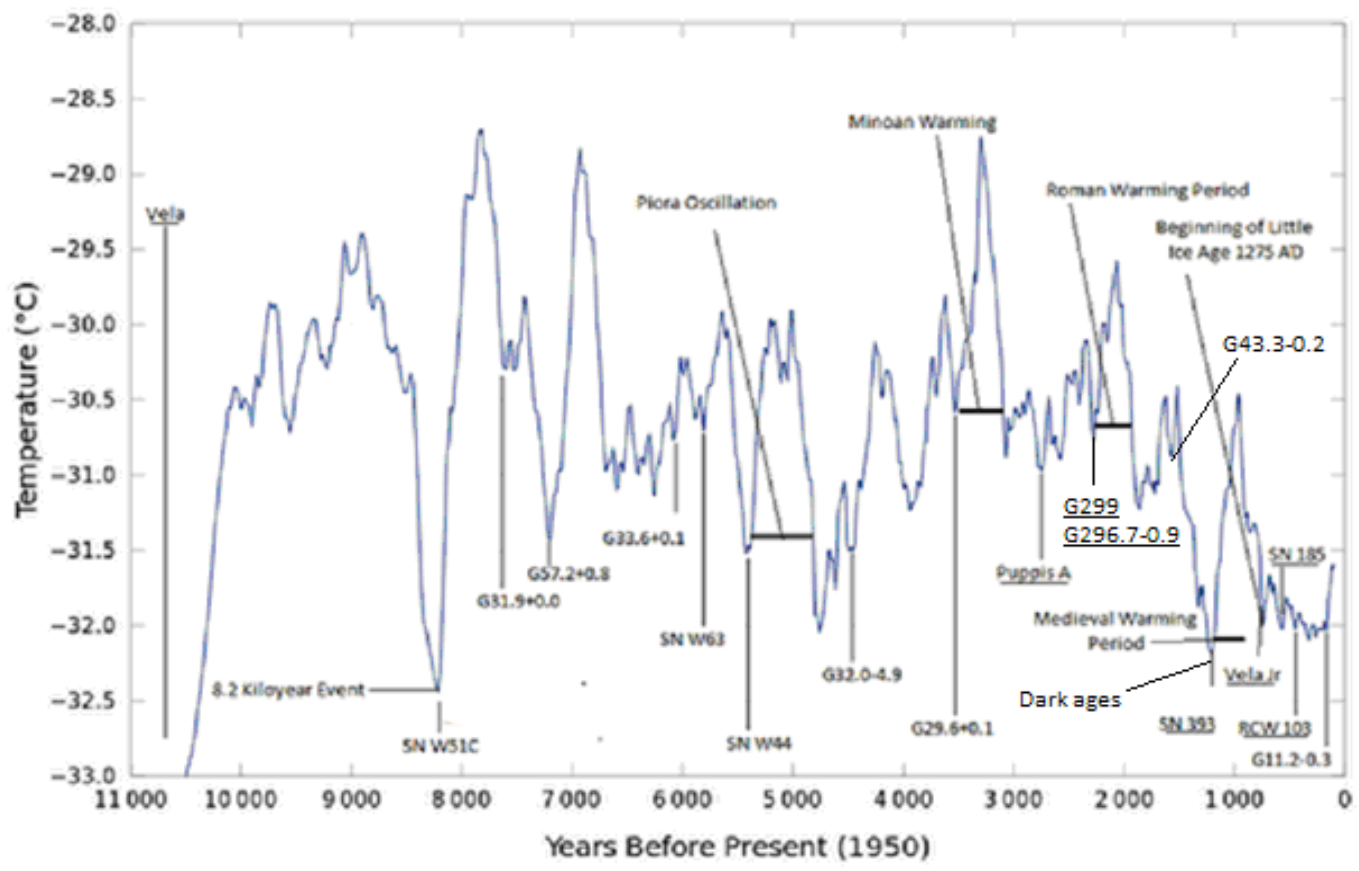

Fig. 4 Greenland ice core temperatures, Kiloyear Event, Piora Oscillation, supernovas, warming periods, Little Ice Age [33].

\subsection{Greenland Ice Core Temperatures and Supernovas}

The proposed supernovas debris stream impact times recognized since the end of the last ice age are shown in Fig. 4. The data in Fig. 4 begin to express the following concepts. The 8.2 Kiloyear Event occurred due to the lack of a northern hemisphere, thermally effective, incoming supernova streams for a time period of approximately 3,000 years resulting in extreme northern hemisphere cooling or an unknown supernova with high iron particle density in its debris stream. SN W51C with a declination of +14 provided incoming thermal energy in the northern hemisphere to end the cooling and increase the Greenland ice core temperatures. SN W44 (declination +1 ) provided the energy required to produce the Piora Oscillation in the northern and southern hemisphere that occurred from 5,200 to 4,900 years ago [14]. Supernovas 393 provided the thermal energy to cause the Medieval Warming Period and even though other supernovas impacted the planet after 1275, the beginning of the Little Ice Age, none were thermally potent enough in the northern hemisphere to end the Little Ice Age until the impact of SN G11.2-0.3 with numerous WZ Sagittae impacts shown in Fig. 3a. Table 3 shows the negative declinations for the supernovas G11.2-0.3, Vela JR, 185, and RCW103. The change of ice volume in the southern hemisphere due to these supernovas is noted in Fig. 3a. Supernovas with negative declinations are underlined in Fig. 4.

\subsection{Transition from Wisconsin Ice Age}

Incoming supernova debris streams cause warming and melting ice caps that produce increased sea levels.

The increase in sea levels that correlates with supernova impact times is shown in Table 5. The reconstruction by Tarasov and Peltier that predicts the melt water coming from North America for melt water pulse 1A, MWP-1A, shown in Fig. 6 is justified by the declination and right ascension of +59 degrees and 99 degrees west longitude for the western terminus' focus for supernova G109.1-1.0 impact at 14,957 ya shown in Table 5 [42]. The calculated time of 14,957 ya agrees exactly with the change of temperature time in Fig. 7. 
Fig. 6 Increase in sea level since last glacial maximum [42].

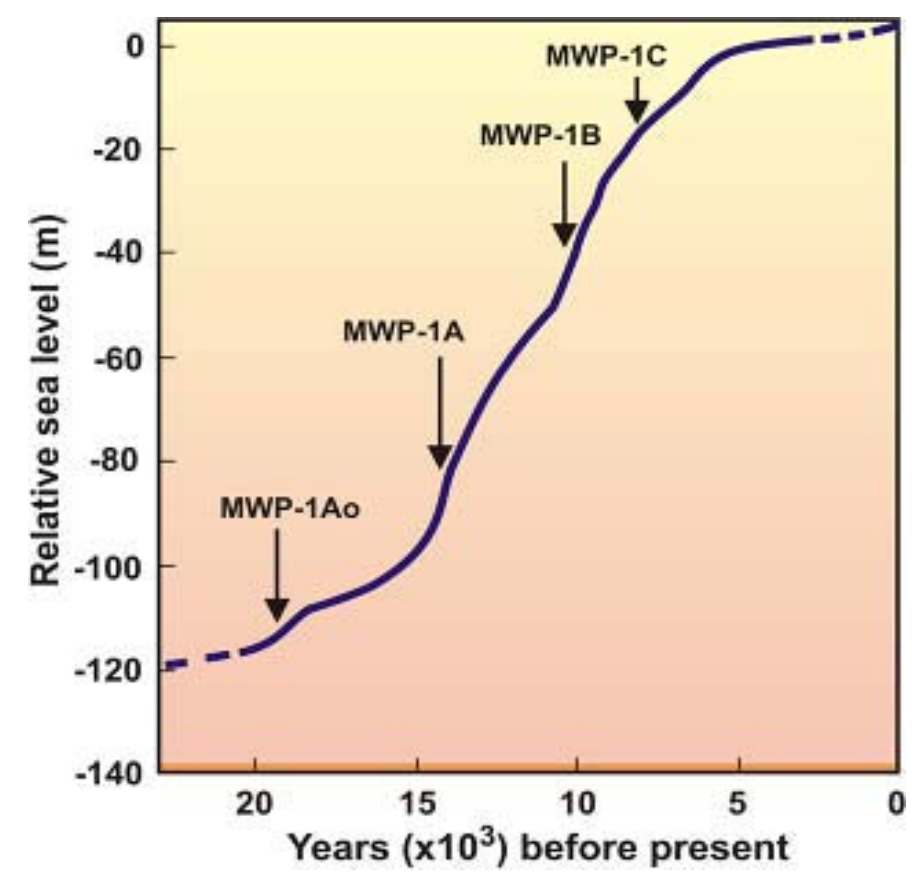

Table 5 Sea level rise and supernova impact times [42].

\begin{tabular}{llll}
\hline Sea level rise, SLR & Time SLR, YBP & Supernova & Impact time, ya, declination, WT, modification \\
\hline MWP-1Ao & 19,000 & HB 21 (G89.0+4.7) & $18,628+50 \mathrm{WT}=73 \mathrm{E} 177 \mathrm{E} 3 \mathrm{~W}$ \\
& & W50 & $17,600+5 \mathrm{WT}=50 \mathrm{E} 168 \mathrm{E} 12 \mathrm{~W}$ \\
MWP-1A & 14,600 to 13,500 & G109.1-1.0 & $14,957+59 \mathrm{WT}=107 \mathrm{E} 99 \mathrm{~W} 81 \mathrm{E}$ \\
MWP-1B & 11,500 to 11,000 & W50 Meteor & 12,800 \\
& & Vela $(800)$ & 11,700 ya $-45 \mathrm{WT}=110.5 \mathrm{~W} 80 \mathrm{E} 100 \mathrm{~W}$ \\
MWP-1C & SN W51C $(\mathrm{G} 49.2-0.7)$ & $8,004+14 \mathrm{WT}=15 \mathrm{E} \mathrm{97W} \mathrm{73E}$ \\
& & G31.9+0.0 $(29,304)$ & $8,092+0 \mathrm{WT}=44 \mathrm{E} 67 \mathrm{~W} 113 \mathrm{E}$ \\
& & G57.2+0.8 $(18,758)$ & $7,498+21 \mathrm{WT}=51.5 \mathrm{E} 52 \mathrm{~W} 128 \mathrm{E}$ \\
\hline
\end{tabular}

The effect on temperature at Greenland during the transition to the Wisconsin Ice Age for a supernova depends on the distance, declination and, right ascension of the remnants. The distance, declination, and right ascension for the remnants, causing increased sea level are shown in Table 5. By requiring the western or eastern terminus at the time of impact in the northern hemisphere to be near Greenland, supernovas G31.9+0.0, and G57.2+0.8 may be thermally effective at Greenland. The number in parenthesis in the name column for these supernovas is the distance from our planet. G31.9+0.0, and G57.2+0.8 distances cause their thermal effectiveness to be minimal at Greenland. The Vela supernova was thermally effective at Greenland, even though the declination is -45 degrees.

It is interesting to note that the Younger Dryas portion of the Wisconsin ice age shown in Fig. 7 was discontinued by the W50 meteor and the Vela supernova because supernova Vela is at a declination of -45 degrees in the southern hemisphere, but produced a large amount of energy on the ice caps of both hemispheres. This occurs because it is the second closest supernova to our planet. The nano-diamond meteor's timing caused energy addition to begin at 12,800 ya and overcame the iron seeding of the Vela supernova; therefore, the planet did not experience cooling from the normal cycle of the Vela supernova [40]. The Vela supernova added energy to the earth's core that was transferred to the surface through the path 


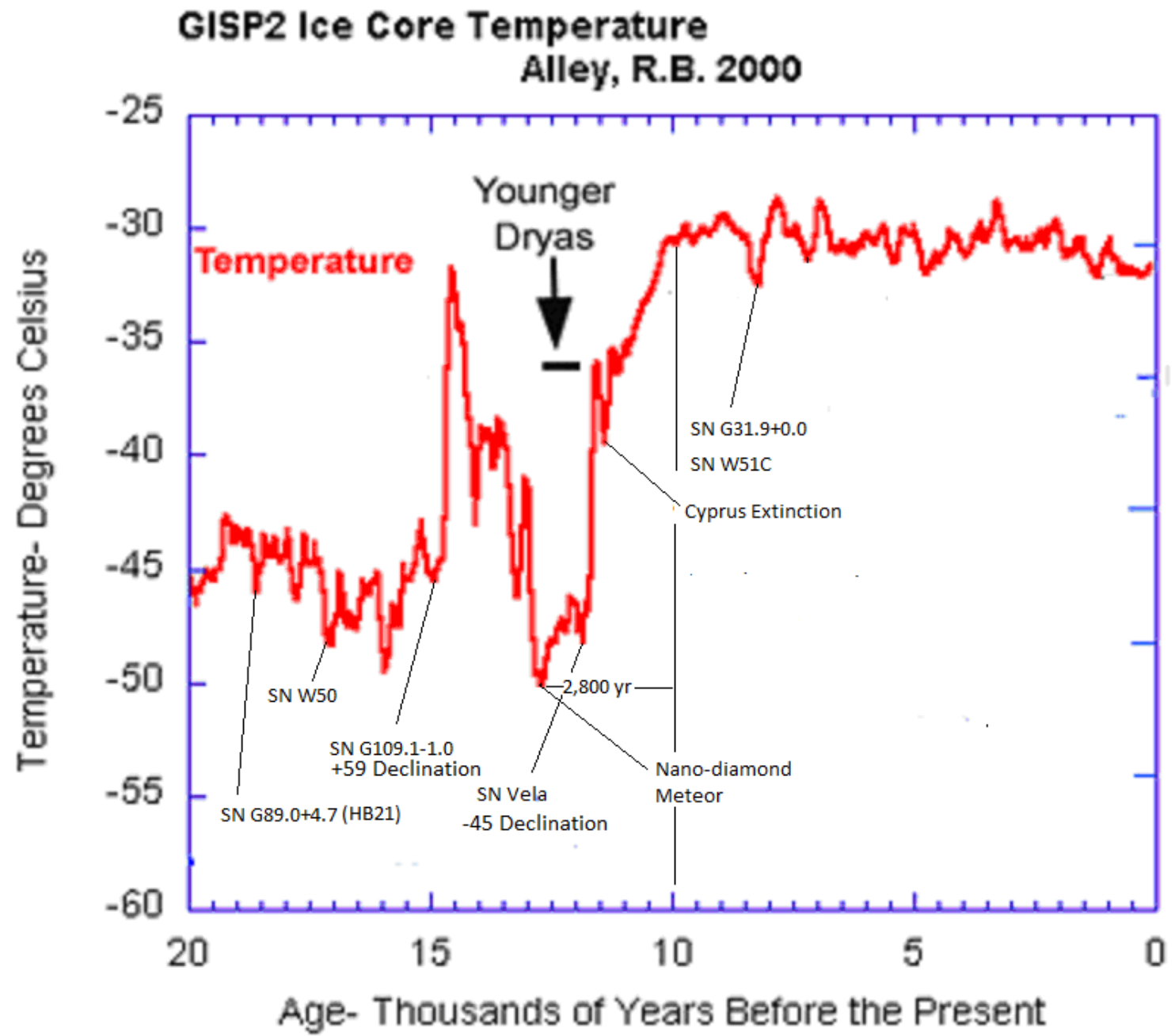

Fig. 7 Greenland ice core temperatures and supernovas (20,000 to 7,000 YBP) [43].

of the meteor through the earth. The results of the meteor impact released energy from the earth's core for 2,800 years, see Fig. 7 .

\subsection{Debris Streams Carbon and Iron Atoms Effects}

All atoms of carbon were produced in stars. The incoming debris must contain many carbon atoms that impact our atmosphere at high velocity and burn producing carbon dioxide. The exothermic reaction releases thermal energy into our atmosphere and global warming results with increasing carbon dioxide levels due to energy from the sun. Since the incoming energy of a supernova melts ice caps, carbon dioxide will increase naturally when the planet transitions from an ice age to a warm period is caused by supernovas. The decrease of carbon 14 percentage as a result of a supernova occurs due to the increase of incoming carbon 12 in the debris streams [35].

Initially, the incoming debris of a supernova or nova guarantees an increased amount of carbon dioxide in our atmosphere. Carbon is a lighter atom than iron and iron is the heaviest atom a star can produce before it becomes a supernova. The iron atom concentration in the debris stream will impact our planet after the carbon atoms and when they enter bodies of water large algae blooms will result. The algae blooms absorb carbon dioxide and produce oxygen. Consider the Minoan Warming of Fig. 4. The incoming carbon from supernova G29.6+0.1 causes the warm up as shown by the increased Greenland ice 
core temperatures. Then the iron particles of the G29.6+0.1 supernova causes the ocean's algae blooms and the carbon dioxide is absorbed and cooling results ending the Minoan warming period. As can be seen in Fig. 4, this is a normal cycle. There is no guarantee that there will be more carbon warming effect or more iron cooling effect, but it can be concluded that the carbon dioxide produced protects us from excessive cooling. Two supernovas, G299 and G296.7-0.9, impacted the earth to produce first the Roman warming period shown in Fig. 4 with the normal cooling and then a third unknown supernova created some warming with a lot of cooling dropping temperature to a minimum near 1,100 years ago $(900$ AD). This cold period produced the Dark Ages. Then SN 393 occurred causing more warming than cooling, but the end result was the Little Ice Age. The Dark
Ages and the Little Ice Age were very disastrous periods of time for our planet's human populations. It should be concluded that the increase in $\mathrm{CO}_{2}$ caused by supernovas 1006 and 1054 that is currently being observed is a boon to mankind and will protect us from the coming cold phase that will be caused by these currently impacting supernovas.

\subsection{Blush or Initial Impact Effect}

It would be correct to say the planet blushes do to the initial impact of a powerful supernova and SN 1006 and the impact year of 2012 is our cited example.

The noted mathematical relations applied to the available data of the active novas and supernovas noted in Table 6 have generated the shown CAM dates and Termini longitude locations. The best example of a blush is shown in Fig. 8.

Table 6 Acting nova and supernova CAM dates, western and eastern termini longitudes.

\begin{tabular}{llll}
\hline Remnant & WT/ET & CAM dates & Longitude \\
\hline SN 1006 & WT & May 2 & $13 \mathrm{~W}$ \\
& ET & November 2 & $167 \mathrm{E}$ \\
SN 1054 & WT & December 12 & $155 \mathrm{~W}$ \\
& ET & June 12 & $25 \mathrm{E}$ \\
WZ Sagittae & WT & July 20 & $65 \mathrm{E}$ \\
& ET & January 20 & $115 \mathrm{~W}$ \\
V606 Aquilae & WT & July 9 & $52 \mathrm{E}$ \\
& ET & January 8 & $128 \mathrm{~W}$ \\
Variation & & Tolerance $\pm 5 \%$ & Deflection $(\mathrm{q} / \mathrm{M})$ \\
Bulge & & Circular area \\
\hline
\end{tabular}

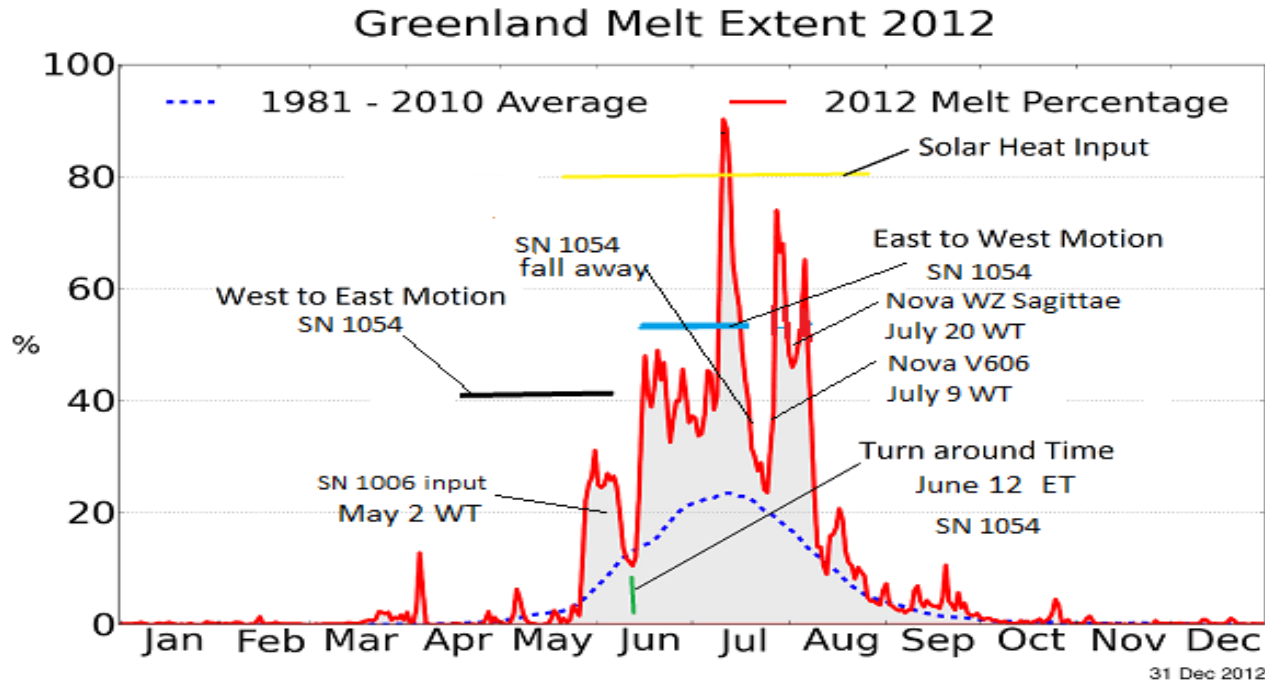

Fig. 8 Blush of SN 1006 with 2012 Greenland melt extent. 
The evidence of different debris streams is noted by the times of changing ice melt shown in Fig. 8. The western terminus of SN 1006 is noted by the melt in early May coinciding with the CAM date of May 2nd. The eastern terminus CAM date of June 12th is close to the time when no debris stream is acting on Greenland and after June 12 the eastern terminus of SN 1054 traveling west melts ice again in Greenland. A large ice melt peak occurs in the latter part of June indicating a missing nova or supernova terminus. After the melting effect of SN 1054 ends or falls away two melt peaks occur at the proper time of the CAM dates for the novas V606 Aquilae and WZ Sagittae. The 2012 impact of SN 1006 caused the highest temperature records ever recorded for our planet and one of the acting debris streams CAM dates is shown for each acting debris stream in the Greenland melts data. This event that is called a blush occurs due to the high density of carbon, helium, and hydrogen particles in the first wave of the SN 1006 debris stream. The blush is an unusual condition but the emphasis requires the planet to be in the particle stream or satisfy a CAM date for a debris stream focal point to exist at any location on the planet.

There are undoubtedly a number of supernova debris effects to still be investigated and other supernova remnants of which the author does not have the necessary data to include them in this study. It is important for further research in this area to be expended by scientist wishing to protect human populations from extreme climate change.

\section{Conclusions}

The fact that extinctions, sunspot minimums, periods of reduced total solar irradiance, and changing hemispherical thermal conditions are results of supernova and nova debris stream impacts with our planet has been established.

It is interesting that the closest supernova, Vela Jr, produces the largest historical disaster for humanity from a distance of 652 lys and supernovas W44 and
G192.8-1.1 cause mega disasters from 10,000 and 13,040 lys, respectively. A number of supernova impacts include periods of aridification and drought that becomes another means of megafauna extinction [28]. Large animals need abundant fresh water for survival. The other method for extinction occurs for the Saiga antelope deaths in 2014 was extensive bleeding from their organs that was caused by supernova debris particles piercing their bodies at high velocities [29].

Even though the effects of a number of the impact events are very impressive, the results of supernovas W44 and Simeis 147 give the Piora Oscillation and Tasmanian Extinction of the Late Pleistocene. These extinction events are outstanding. The incoming debris impact of the Vela supernova that impacted at 11,700 ya marks the beginning of the Holocene Epoch and the end of the Younger Dryas Ice Age with the beginning of the current warm period starting 10,000 years ago [30]. Supernovas and the W50 meteor have produced a warm planet for our civilization to become farmers feeding a large human population.

Since supernovas 1054 and 1006 are currently incoming, the planet's average temperatures should continue to increase, global warming. Global warming will not be reduced by reducing man made $\mathrm{CO}_{2}$ emissions and in reality the only defense is to move to a cooler hemisphere, harvest $\mathrm{CO}_{2}$ from the atmosphere, or stop the incoming particles.

Since the Siaga antelope deaths are attributed to incoming supernova debris, an epidemic should exist in the human population due to supernova debris near 2015. Chikungunya, the bending disease has increased in occurrences through 2014-2016 [32].

Applying Occam's razor, supernova debris impact is the simplest method that explains all these extinction and biosphere disturbance events because the only assumption is all debris streams travel at the same velocity from the remnant to our planet.

If all the age, distance, declination, and right ascension data were accurately known, the past effects 

Melts and Biosphere Mega-disturbances-Global Warming

of space weather could be correlated and amazing future predictions would result.

Any model that claims to know the energy source for global warming must predict the past effects like Antarctic melts in Fig. 3a. Then the model can be successfully used to predict global warming effects in the future. If the proposed model cannot predict past global warming events from previously recorded independent data, the model is useless.

The SNIT model shows unusual and distinct conditions for beginning and ending ice ages. To start an ice age, a close supernova explosion like SN Monogem Ring must produce an extreme amount of iron on earth's surface. To end an ice age a meteor from a supernova explosion must penetrate earth's mantle and release geothermal energy over a long period of time to melt the ice.

Our government officials are sworn to protect the people and they have less than 100 years to learn how to deflect the destructive particle stream from GK Persei or millions of people will die possibly in many different nations. The debris streams of supernovas 1006 and 1054 have already began to destroy life on earth. When President Obama received a rough draft of this work, he issued an executive order to NASA stating, "Space weather has the potential to simultaneously affect and disrupt health and safety across entire continents" [41]. When will we learn to quit killing each other and fight the major danger for humanity that comes from outer space?

\section{References}

[1] https://en.wikipedia.org/wiki/Neutrino_detector.

[2] https://en.wikipedia.org/wiki/RX_J0852.0-4622.

[3] http://www.historytoday.com/ole-j-benedictow/black-dea th-greatest-catastrophe-ever.

[4] https://en.wikipedia.org/wiki/List_of_supernova_remnant s.

[5] http://news.nationalgeographic.com/news/2015/01/15011 3-mass-die-off-disease-animals-environment-science/.

[6] http://www.nytimes.com/2015/11/03/science/more-than-h alf-entire-species-of-saigas-gone-in-mysterious-die-off.ht $\mathrm{ml}$ ? $\mathrm{r}=0$.

[7] http://www.theverge.com/2016/8/29/12688614/lightning- strike-kills-reindeer-norway.

[8] https://en.wikipedia.org/wiki/Megafauna.

[9] The Oxford Companion to Archaeology, Brian M. Fagan pg 433.

[10] https://en.wikipedia.org/wiki/SN_386.

[11] A History of Bubonic Plague in the British Isles, J. F. D. Shrewsbury pg 11.

[12] https://www.cemml.colostate.edu/cultural/09476/egypt02 -05 enl.html.

[13] http://adsabs.harvard.edu/abs/1997ApJ...488..781H.

[14] https://en.wikipedia.org/wiki/Piora_Oscillation.

[15] http://www.davidfurlong.co.uk/3100bc.htm.

[16] https://en.wikipedia.org/wiki/Solar_minimum.

[17] http://cc.oulu.fi/ usoskin/personal/aa7704-07.pdf.

[18] http://arxiv.org/pdf/1103.4958v2.pdf.

[19] http://adsabs.harvard.edu/full/2002aprm.conf..235Y.

[20] https://en.wikipedia.org/wiki/Fourth Dynasty_of Egypt.

[21] https://en.wikipedia.org/wiki/5.9_kiloyear_event.

[22] http://www.businessinsider.com/why-last-woolly-mamm oths-went-extinct-2016-8.

[23] http://www.dailymail.co.uk/sciencetech/article-3432060/ An-unknown-chapter-human-history-took-place-Europe15-000-years-ago-DNA-shows-hunter-gatherers-replaced -mystery-group-people-Ice-Age.html.

[24] https://en.wikipedia.org/wiki/Patagonian_Ice_Sheet.

[25] https://en.wikipedia.org/wiki/4.2_kiloyear_event.

[26] https://en.wikipedia.org/wiki/8.2_kiloyear_event.

[27] https://en.wikipedia.org/wiki/Last_Glacial_Maximum.

[28] https://www.sciencedaily.com/releases/2006/11/0611280 93019.htm.

[29] http://www.theblaze.com/stories/2015/09/04/unheard-ofmass-death-that-wiped-out-60000-endangered-antelope-i n-four-days-still-baffles-scientists/.

[30] https://en.wikipedia.org/wiki/Holocene.

[31] http://www.livescience.com/28954-ancient-europeans-my steriously-vanished.html.

[32] http://edis.ifas.ufl.edu/in722.

[33] https://en.wikipedia.org/wiki/Medieval_Warm_Period.

[34] http://www.bible.ca/archeology/bible-archeology-exodusdate-1440bc.htm.

[35] http://www.c3headlines.com/are-todays-temperatures-un usual/.

[36] http://news.nationalgeographic.com/2016/04/160412-icesheet-collapse-antarctica-sea-level-rise/.

[37] http://dspace.stir.ac.uk/handle/1893/1309\#.V 5jY8sXLcs.

[38] https://arxiv.org/abs/1607.05652.

[39] http://articles.adsabs.harvard.edu/full/1996Ap\%26SS.243 $. .371 \mathrm{H} / 0000372.000 . h t m l$.

[40] https://en.wikipedia.org/wiki/Younger_Dryas_impact_hy pothesis.

[41] http://www.newsweek.com/obama-orders-government-pl an-extreme-space-weather-509891. 

Melts and Biosphere Mega-disturbances-Global Warming

[42] http://www.giss.nasa.gov/research/briefs/gornitz_09/.

[43] http://www.ncdc.noaa.gov/paleo/pubs/alley2000/.

[44] http://www.actforlibraries.org/new-study-suggests-earth- hit-by-gamma-ray-blast-1200-years-ago/.

[45] http://www.messagetoeagle.com/windover-pond-remarka ble-8000-year-old-underwater-cemetery-in-north-america/ 